\title{
HYPERPYREXIA IN THE POST-KERNIKTERUS SYNDROME
}

\author{
BY \\ W. H. PATTERSON and R. M. FORRESTER \\ From Booth Hall Hospital, the Royal Manchester Children's Hospital and the Department of Child Health, \\ University of Manchester
}

(RECEIVED FOR PUBLICATION FEBRUARY 10, 1953)

Since Guthrie's description in 1914 it has been clear that if an infant survives the initial illness of icterus gravis neonatorum, and particularly if he has shown signs of neurological disturbance at the height of his jaundice, he is liable to suffer from permanent derangement of the central nervous system. Sobel and Zucker (1940) described the characteristic clinical tetralogy of choreoathetosis, extrapyramidal spasticity, opisthotonus and mental defect. This article describes further manifestations of the postkernikterus syndrome occurring in seven infants. The main features were attacks of hyperpyrexia, sweating and head retraction without evidence of infection; in the majority the attacks were repeated many times, and, in all but one, death occurred during an attack. An eighth case occurred in an infant with acholuric jaundice, and in a ninth case the aetiology is uncertain. Four of the cases we have observed ourselves; for the details of the others we are indebted to the physicians who have given us access to their case records.

The nomenclature in this condition suffers from the fact that the term 'kernikterus' was originally limited to the naked-eye appearance of the nuclear masses. It is proposed in this article to limit the use of the word to its original meaning. The term 'clinical kernikterus' will be used to describe the original illness where a jaundiced infant shows the characteristic neurological signs, and the term 'postkernikterus syndrome' for the cases of the survivors who show permanent changes.

\section{Case Histories}

Case 1. C.S. was the fifth child of normal parents. The siblings were normal. Delivery was normal at full term (birth weight $71 \mathrm{lb}$.). The infant was normal at birth, but iaundice was noted within 24 hours. When admitted to hospital on the fourth day she was comatose, spastic and deeply jaundiced. She had grunting respirations and a temperature of $102^{\circ} \mathrm{F}$. Haemoglobin was $100 \%$. The infant was Rh positive (D positive). The direct Coombs test was positive. The mother was $R h$ negative (D negative). The Wassermann and Kahn tests were negative. The cerebrospinal fluid was xanthochromic.

The infant had several minor convulsions but settled with oxygen therapy. Over the next two weeks the haemoglobin fell to $58 \%$, but the jaundice gradually cleared and her general condition improved. A transfusion of $120 \mathrm{ml}$. Rh-negative blood was given, and repeated after 11 days because of a further fall in haemoglobin.

The baby remained fairly well until the age of $4 \frac{1}{2}$ months, when she was readmitted with the story that she was constipated, refusing feeds, twitching and sweating. On admission she had a temperature of $102^{\circ} \mathrm{F}$., pulse 150 , respiration 50 . She had head retraction which could be overcome with steady pressure. She was sweating violently. Nothing was discovered to account for the fever. The white cell count, urine and C.S.F. were normal.

Over the next three days the fever settled without specific treatment. It was noted that the head retraction continued after the temperature fell, and that she did not show the normal responses for her age.

From this time until her death at the age of $16 \frac{1}{2}$ months, she was readmitted to hospital 10 times. On each occasion she was pyrexial and head retraction was noted. Apart from one incident when there was a strong suspicion of otitis media no evidence of infection was ever discovered. She was usually constipated and, at the beginning of the attack, dyspnoeic, but the most notable feature of each attack was the profuse sweating. In the attacks her temperature usually remained between $101^{\circ}$ and $102^{\circ} \mathrm{F}$. without remission for three to four days, despite the use of a wide range of antibiotics in adequate dosage. Her temperature usually fell suddenly to normal; she would start taking feeds again and would be fit to return home in a few days.

Throughout the last 12 months of life there were intermittent bouts of generalized spasticity and twitching of the arms, and there were several major convulsions. There was no real mental progress. She continued to gain weight slowly and weighed $15 \mathrm{lb}$. just before her death in a typical attack. No necropsy was obtained.

Case 2. P.McC. suffered from icterus gravis neonatorum. During the initial illness he had head retraction. 
At the age of $4 \frac{1}{2}$ months he was readmitted because of attacks of screaming and vomiting. He had a temperature of $104^{\circ} \mathrm{F}$. and pulse of 160 ; his respirations were 48 per minute. He was spastic and there was head retraction; there were some generalized twitchings, and a few minor convulsions occurred. There was neither clinical nor laboratory evidence of infection, and the symptoms settled over the next few days without specific treatment. His mental development was retarded.

At the age of 7 months a similar attack occurred. He was admitted with a temperature of $105^{\circ} \mathrm{F}$. and respiratory rate of 60 . He was sweating profusely and there was marked constipation. This attack settled without evidence of infection and without specific treatment. During the next three months he remained in hospital and three more attacks were fully observed. At the age of 11 months he was readmitted in a similar state. He had several major convulsions and died within 48 hours. No evidence of infection was found at necropsy. On nakedeye examination the brain appeared normal; no histology was done.

Case 3. J.R. suffered from icterus gravis neonatorum and developed head retraction and a temperature of $106 \cdot 8^{\circ} \mathrm{F}$. On the third day of life. When she left hospital at the age of 3 weeks there was some general spasticity, and a minor degree of head retraction remained.

She was readmitted at the age of 10 weeks and again at 13 weeks with sudden attacks of crying and fever. Her temperature rose on each occasion to $104^{\circ} \mathrm{F}$. and respirations to 50 . There was profuse sweating and marked constipation, but there was neither clinical nor laboratory evidence of infection. She did not have normal responses for her age. At the age of 15 weeks she was admitted after a convulsion with a temperature of $102 \cdot 5^{\circ} \mathrm{F}$. and respirations of 64 : she died the same day. At necropsy no evidence of infection was found. On naked-eye examination the brain appeared normal: no histology was done.

(A subsequent sibling who was also affected with haemolytic disease died in the neonatal period: classical kernikterus was demonstrated.)

Case 4. I.W. suffered from icterus gravis neonatorum and had marked head retraction from the fourth to the eighth day of life. He was readmitted to hospital at the age of $4 \frac{1}{2}$ months with retraction and fever. No evidence of infection was found, but he remained intermittently pyrexial-with a maximum of $106^{\circ}$ F.- until he died eight days after admission. At necropsy the only positive finding was basal consolidation of the lungs. The brain appeared normal on naked-eye examination.

Case 5. M.S. suffered from icterus gravis neonatorum. An exchange transfusion was performed at the age of 12 hours. No neurological disturbances were noted in the neonatal period. At the age of 1 year it was noted that she showed marked mental retardation.

She was admitted to hospital at the age of 16 months after seven days of irritability and vomiting. Her temperature was $103^{\circ} \mathrm{F}$.; there was marked head retraction and she was twitching. There was no evidence of infection. Her temperature rose to $107^{\circ} \mathrm{F}$., and at this point she died. At necropsy the brain and meninges appeared con- gested and the C.S.F. was excessive. There was no evidence of infection.

Case 6. S.M. suffered from icterus gravis neonatorum. On the fifth day of life he had marked neck stiffness.

At the age of 4 months he was admitted with a history of vomiting. His temperature was $100 \cdot 2^{\circ} \mathrm{F}$. and soon rose to $106 \cdot 8^{\circ} \mathrm{F}$. There was hypertonicity and neck retraction: he had several convulsions. There was no evidence of infection, and he slowly settled, although he remained spastic. Five weeks later he had a further bout with a temperature of $105 \cdot 4^{\circ} \mathrm{F}$., violent sweating and convulsions. A week later he had his third typical bout but remains alive at the time of writing. He is spastic and apparently blind.

Case 7. P.J. was a week premature. He was not jaundiced in the neonatal period. His mother, however, noted that he always appeared to lie with his head pulled back.

He was reported to have made normal progress until the age of 4 months when he was admitted to hospital after three days' irritability, fever, vomiting and convulsions. He had head retraction and was generally spastic; he sweated violently and was very constipated: there was marked dyspnoea. He had a well marked plagiocephaly. There was no evidence of infection apart from a swollen gland in the neck. Over the next three months he was readmitted to hospital four times in a similar state. Air encephalograms showed slight general dilatation of the ventricles. He died in an attack with a temperature of $107.5^{\circ} \mathrm{F}$. At necropsy there was no evidence of infection.

Case 8. A.McC. suffered from icterus gravis neonatorum. She was drowsy and had neck retraction for three days in the neonatal period.

At the age of 4 months she was readmitted with a history of vomiting. Her temperature rose to $105^{\circ} \mathrm{F}$. and respirations to 60 : she sweated violently. There was no evidence of infection. Three weeks later a further bout settled rapidly.

At the age of 8 months she was readmitted because of vomiting; her temperature rose to $105 \cdot 6=\mathrm{F}$. She sweated violently and there was neck retraction. She died in a convulsion 24 hours later.

Case 9. C.G. suffered from acholuric jaundice. He became jaundiced on the third day of life and was drowsy for several days.

At the age of $5 \frac{1}{1}$ months, after a circumcision under general anaesthesia, he developed a temperature of $104^{\circ} \mathrm{F}$. with rigidity of the lower limbs and neck. This settled in $\mathbf{4 8}$ hours but three days later his temperature rose to $105^{\circ} \mathrm{F}$. and he was generally spastic. He settled without evidence of infection, but it was then noted that he did not show the normal responses for his age.

A month later he was admitted because of failure to make progress. After two days his temperature rose to $105^{\circ} \mathrm{F}$. and he sweated violently. At this stage an air encephalogram showed moderate dilatation of the lateral ventricles. Three further bouts occurred over the next 12 days and in the last he died with a temperature of $105^{\circ} \mathrm{F}$. At necropsy there was a moderate degree of ventricular dilatation. The lungs showed scattered areas 
of consolidation but there was no other evidence of infection.

The course of the illness and the details of the attacks were remarkably similar in these nine infants. The attacks were sudden in onset and were sometimes ushered in by a convulsion. There was hyperpyrexia, tachypnoea and tachycardia. There was often a sweat rash during the acute episode, and in one case this went on to peeling of the hands and feet. Head retraction either appeared during the attacks or in some cases merely became more marked. The most striking feature in six cases was the sweating. During the attacks these infants were covered with beads of sweat; their clothes and pillows were soaked and they were extremely flushed. Intermittent convulsions were common. Until their terminal episodes most of the infants remained in a fair state of nutrition. It was remarkable how suddenly each attack subsided and how with a return to normal temperature the infants resumed what was for them normal behaviour.

In six of our cases the first recorded episode occurred between the age of 4 and 5 months. A 'silent period' after the neonatal jaundice was described in relation to other manifestations by Evans and Polani (1950), although in their cases the first clear symptoms usually appeared before the age of 3 months.

In many ways the episodes we have described were a recapitulation of the events which most of the infants had survived in the neonatal period.

The main findings are summarized in Table 1.

\section{Special Features in Three Cases}

There were certain special features in three of the cases which need further comment.

Case 7. The clinical syndrome was indistinguish- able from that in the other eight cases. There was no evidence of $R$ hesus incompatibility. There was no history of neonatal jaundice, but the evidence about this period of his life is not clear. It seems possible that the central nervous system may have been subjected to the same influences which were associated with a more rapidly fatal outcome in the cases of kernikterus of prematurity described by Aidin, Corner and Tovey (1950) and Zuelzer and Mudgett (1950).

The brain in this case was subjected to a detailed examination. No histological changes could be demonstrated.

Case 8. The history and clinical picture in this case were typical of the majority of the series. This was the last patient in the series to die, and the brain was examined in the full awareness of the clinical syndrome. For the following report on the brain we are indebted to Dr. H. B. Marsden.

'BRAIN. There was marked congestion of the cortical vessels of the brain.

Sections were taken through the pons, medulla, cerebellum, basal ganglia, frontal, temporal, parietal and occipital cortex and the hypothalamus. There was dilatation of the vessels throughout, this feature being most marked in the capillaries of the dentate nucleus. The vessel walls occasionally showed slight swelling with hyaline change. Small perivascular haemorrhages were readily noted and there was loss of structure in the tissues surrounding the vessels in some places. No "cuffs" were seen round the vessels but a perivascular glial focus and very rarely an isolated collection of small glial cells would be found. There was some eosinophilic swelling (on haematoxylin and eosin-stained sections) of the cytoplasm of glial cells although this was not a prominent feature. The neurons throughout had a swollen, indistinct appearance with poor staining qualities, although it was not possible to say how much of these changes was due to artefact.

TABLE 1

SUMMARY OF CHIEF CLINICAL FINDINGS

\begin{tabular}{|c|c|c|c|c|c|c|c|c|c|c|c|c|c|c|}
\hline \multicolumn{6}{|c|}{ Case } & c.s. & $\stackrel{2}{\text { P.MoC. }}$ & $\begin{array}{l}3 \\
\text { J.R. }\end{array}$ & I. 4 : & M.S. & S. $\stackrel{6}{\mathrm{M}}$ & P.J. & $\stackrel{8}{\text { A.McC. }}$ & C.G. \\
\hline Clinical kernikterus & .. & . & . & .. & . & - & + & - & - & $\mathbf{0}$ & - & 0 & - & $\mp$ \\
\hline Age (months at first epi & sode) & . & . & . & . & $4 \frac{1}{2}$ & $4 !$ & $2 \frac{1}{2}$ & $4 !$ & 16 & 4 & 4 & 4 & $5 !$ \\
\hline Age (months at death) & . & . & . & . & . & $16 \frac{1}{2}$ & 11 & 31 & 43 & 16 & alive & 7 & 8 & 7 \\
\hline No. of incidents & $\ldots$ & . & . & . & . & 11 & 6 & 3 & 1 & 1 & 4 & 5 & 3 & 5 \\
\hline Sweating $\ldots$ & . & .. & . & . & . & - & - & - & 0 & 0 & - & - & - & $\mathbf{0}$ \\
\hline Neck retraction & . & $\ldots$ & . & . & $\ldots$ & - & - & - & - & - & - & - & - & - \\
\hline Convulsions & . & . & . & . & . & - & - & - & $\mathbf{0}$ & - & - & - & - & 0 \\
\hline $\begin{array}{c}\text { Mental and or nervous } \\
\text { attacks } \\
\end{array}$ & $\begin{array}{l}\text { chang } \\
\text {. }\end{array}$ & bet & $\begin{array}{l}\text { sen } \\
\ldots\end{array}$ & & e. & - & - & - & $?$ & - & - & - & - & - \\
\hline Highest recorded temper & rature & F.) & . & & $\ldots$ & 102 & 105 & $106 \cdot 8$ & 106 & 107 & $106 \cdot 8$ & $107 \cdot 5$ & $105 \cdot 6$ & 105 \\
\hline
\end{tabular}


'The changes in the basal ganglia and hypothalamus did not differ from those elsewhere. There was possibly some diminution of nerve cells in the basal ganglia although this could not be satisfactorily assessed. The nuclear masses in the hypothalamus, although showing evidence of small recent haemorrhages, were well represented.'

Case 9. This child came from a family known to suffer from acholuric jaundice. The grandfather and the mother both had had the spleens removed; an elder brother had had the spleen removed in childhood, and a subsequent sibling showed evidence of the disease in the neonatal period. In the latter infant a splenectomy was successfully performed at the age of 5 weeks.

In the patient C.S. jaundice appeared on the third day of life. The mother and child were both $R h$ positive and there were no maternal Rhesus antibodies. The spleen became palpable in the neonatal period and the red cell fragility both then and at the age of 6 months was abnormal. (Haemolysis began in $0.5 \%$ and was complete in $0.35 \%$ saline.)

In the neonatal period the picture of deep jaundice and drowsiness suggested clinical kernikterus. Before the baby died it was possible to observe the classical features of the post-kernikterus syndrome, as he was mentally retarded and showed athetotic movements. He was spastic, and the few teeth visible when he died showed definite discoloration although they were not recorded as being the usual green. Sections of the brain were examined in detail at a considerably later date, and for the following report we are indebted to Dr. H. B. Marsden.

'Brain. Many of the features seen in Case 8 were noted although haemorrhages were not seen and there was colloid material in the dilated perivascular spaces. Eosinophilic swelling of the cytoplasm of the glial cells was very noticeable. The capillary dilatation in the dentate nucleus was extreme. Adequate sections for full examination were not taken and there were no blocks from the hypothalamus. The appearances were regarded as being compatible with the effects of hyperpyrexia.'

Although acholuric jaundice has often been noted in the neonatal period there does not appear to be any previous description of its relation to kernikterus. The condition was mentioned by Evans and Polani (1950) only to exclude it as a possible cause.

\section{Discunsion}

Previous descriptions of the post-kernikterus syndrome have drawn attention to lesions in the basal ganglia and hypothalamus. In mammalian temperature control the importance of the latter region is well established. Morgan (1938) and Morgan and Vonderahe (1939) suggested that the mammillo-infundibular nuclei were the most im- portant centres. Disturbances of temperature control ${ }^{*}$ might thus be expected as features of the syndrome and the tendency has been noted by several authors.

Zimmerman and Yannet (1935) described a child with the classical post-kernikterus syndrome who suffered from frequent attacks of pyrexia-with temperatures up to $106^{\circ} \mathrm{F}$.- without evident cause. She died at the age of 3 years after having had a temperature of 102 to $106^{\circ} \mathrm{F}$. almost continuously for the final five months. At necropsy there was no evidence of infection. There was a variable degree of destruction in the cellular elements of the basal ganglia, and special attention was drawn to the lesions in the mammillo-infundibular nuclei of the hypothalamic group.

Yannet and Lieberman (1946) reported a similar case, where the child died at the age of $3 \frac{1}{2}$ years. At necropsy the changes were identical with those described by the previous authors.

Crigler and Najjar (1952) described the occurrence of kernikterus in a type of familial non-haemolytic jaundice. Out of seven children so affected four died during febrile episodes not apparently due to infection. Aidin, Corner and Tovey (1950) noted that hyperpyrexia was a common feature in the terminal stages of their cases of kernikterus in the premature infant.

Pyrexia of central origin is a well recognized phenomenon. Erickson (1939) described 20 fatal cases with varying lesions in the nuclear masses. The major features of the clinical syndrome were the absence of sweating and the coldness and pallor of the extremities, suggesting that there had been paralysis of the centres controlling heat loss. This picture contrasts markedly with that in our own cases where fever was accompanied by profuse sweating and flushing. We must explain this feature by postulating that the centres for heat loss were intact, but that the centres for heat production were in a state of intermittent excitement corresponding to the clinical episodes. It is impossible to state whether each episode was spontaneous, but it is possible that very minor disturbances or infections may have acted as a trigger on some occasions.

The occurrence of clear histological changes in every case would have helped to make the full picture of the syndrome clearer. Most of the cases were reviewed in retrospect, however, and the detailed material was not available.

We do not feel that this lack of histological confirmation invalidates the clinical concept.

- Since the completion of this article our attention has been drawn to the excollent review of kernikterus by Gerrard (Brain, 75, 526), where faulty temperature regulation is acknowledged as a frequent feature of the post-kernikterus syndrome. 


\section{Summary}

A syndrome in infants is described where the main features were neck retraction, profuse sweating and hyperpyrexia of central origin.

Of nine cases described, eight were fatal. In eight there had been severe neonatal jaundice and of these six had shown definite evidence of nervous involvement ('clinical kernikterus') in the neonatal period.

Seven of the infants had suffered from haemolytic disease of the newborn.

One of the infants suffered from familial acholuric jaundice.

The possible mechanism of the disturbance is discussed.

We should like to thank the following physicians for permission to include details of cases under their care: Dr. Sylvia Guthrie, Dr. A. Holzel, Dr. R. I. MacKay, Dr. Margaret Egan, Dr. G. M. Komrower, Dr. M. L. Thomson and Dr. D. M. Anderson.
We are grateful to Professor W. F. Gaisford for advice and criticism and for permission to publish his cases, including in particular that of the infant with acholuric jaundice.

Dr. G. J. Crawford and Dr. A. G. Hesling have been of great assistance in collecting material and information for us.

Finally we would like to thank the innumerable house officers upon whose careful and detailed notes we have so often depended.

\section{REFERENCES}

Aidin, R., Corner, B. and Tovey, G. (1950). Lancet, 1, 1153.

Crigler, J. F., Jr. and Najjar, V. A. (1952). Pediatrics, 10, 169.

Evans, P. R. and Polani, P. E. (1950). Quart. J. Med., n.S., 19, 129

Erickson, T. C. (1939). Brain, 62, 172.

Guthrie, L. (1914). Proc. roy. Soc. Med., 7, (Sect. Study Dis. Child.), 86.

Morgan, L. O. (1938). J. Neurophysiol., 1, 281.

and Vonderahe, A. R. (1939). Arch. Newrol. Psychiat., Chicago. 42, 83.

Sobel, I. P. and Zucker, J. M. (1940). J. Pediat., 16, 445.

Yannet, H. and Lieberman, R. (1946). J. Amer. med. Ass., 130, 335.

Zimmerman, H. M. and Yannet, H. (1935). Amer. J. Dis. Child., 49, 418.

Zuelzer, W. W. and Mudgett, R. T. (1950). Pediatrics, 6, 452. 